\title{
Exergy analysis applied to performance of buildings in Europe.
}

\author{
K Sartor ${ }^{\mathrm{a},}$, P. Dewallef ${ }^{\mathrm{a}}$, \\ ${ }^{a}$ Aerospace and Mechanical Engineering Department - Laboratory of Thermodynamic and \\ Energetic, University of Liège, 17 Allée de la découverte, 4000 Liège, Belgium
}

\begin{abstract}
Energy performance of buildings generally assesses the energy consumption of buildings such as heating, domestic heat water, ventilation systems, etc. However, this approach is based on the first law of thermodynamics and considers only the quantity of energy used without considering its 'quality' and leads to a lack of information about the energy conversion processes. This is particularly true in the new low-energy buildings where sometimes high temperatures sources are used to meet low-temperature needs. The exergy analysis of a system, based on first and second thermodynamic laws, can be used to overcome this. In this work, it is proposed to compare the energy and the exergy consumption and the related $\mathrm{CO}_{2}$ emissions of several kinds of buildings to determine the best systems in terms of energy and exergy needs. The energy demand calculations are performed using the official software available in Belgium and some assumptions are implemented to consider the exergy approach. As exergy calculations require a reference state, some different climatic conditions are also investigated. Finally, some conclusions are discussed to rank the sources of energy and their related exergy losses.
\end{abstract}

Keywords: exergy analysis, building performance, exergy, $\mathrm{CO}_{2}$ reduction, heat sources.

\section{Introduction}

About $40 \%$ of the Europe energy is dedicated to the buildings [1,2] and represents about $36 \%$ of the $\mathrm{CO}_{2}$ emissions. Therefore European Union sets up the Directive 2002/91/EC, reinforced in 2010 by Directive 2010/31/EU to try to improve the performance of the buildings and to reduce the energy 
consumption and greenhouse gases such as $\mathrm{CO}_{2}$ emissions. Each state member had to determine some minimum requirements for new buildings and to rank the existing ones. In Belgium, dedicated software has been created to rank the buildings' performance and expressed energy performance based on the primary energy use. This software assesses the energy consumption of buildings such as heating, domestic hot water (DHW) or ventilation needs. However, energy requirements of residential buildings and for a large variety of office buildings are generally on a low-grade, meaning that it is possible to use low quality energy sources. This is due to that space heating and DHW preparation do generally not require more than $55^{\circ} \mathrm{C}$ supply temperature in conventional and low energy buildings [3]. In older buildings, space heating can require higher temperature such as $75^{\circ} \mathrm{C}$, which remains lowgrade energy. This is due to old heating systems such as convectors (without fans) and radiators with low heating area. But the way of production of heat use generally high-grade energy i.e. electricity or fuel in a combustion process which reaches $1500{ }^{\circ} \mathrm{C}$ [4]. In this case, the energy conversion of this combustion process is currently close to one but the quality of the energy is widely degraded. Indeed the use of the energy analysis to rank a system is often misleading because it does not always provide an indicator how the system is near the ideality [5]. But the exergy analysis, which is detailed later in this paper, does because it is based on the first and the second laws of thermodynamics and states that despite the energy cannot be created or destroyed, its quality can be degraded up to an equilibrium state with the surroundings.

As previous stydy [? ], it is proposed to investigate the energy and the exergy needs as building performance indicators to rank the buildings and to point out the degradation of the exergy supplied to buildings. In this contribution, a larger panel of heating systems solutions are considered to assess the best system to minimize energy and exergy consumption based on Belgian data but this study can be extended to other countries considering databases such as [6-8]. Moreover several kind of building involving different nominal energy requirements are considered to extend the present study. The point is to compare each building current situation to all the heating systems investigated. The building choice is set to try to represent the Belgian building stock. Notice two terraced buildings are selected, one with insulation and the other without while it is important to point out the major influence of the insulation on the energy needs. While the exergy depends on a reference temperature, it is also proposed to investigate some different climatic 
conditions to assess their influences. Finally, the related $\mathrm{CO}_{2}$ emissions are also calculated to rank the heating systems.

\section{Problem statement}

\subsection{Energy analysis}

Building energy performance can be assessed by the amount of energy required to maintain users comfort inside the building. To assess this amount of energy needs, an energy balance is set up. There are heat losses due to transmission (walls, roof, ground...) and due to free or forced ventilation. Concerning the ambient, average values of outside temperatures are considered month by month. The heat losses can be fully or partly compensated by the energy gains such as appliances, users or solar gains through openings. For the solar energy gains, surface orientation are considered for each surface. The reader interested can refer to [9] to access to all Walloon Region regulations about energy building performance and the related detailed calculations performed in the software. The heating needs calculations are not focussing in this contribution while the major aim deals with the exergy degration in fonction of the heating systems.

The main indicator provided by the EPB software is the primary energy

use per square meter of the building (specific energy use) expressed in $\mathrm{kWh} / \mathrm{m}^{2} /$ year. The primary energy use is divided into the heating energy needs, the efficiency of the heating systems, the DHW energy needs, the consumption of auxiliaries (pump, electronic devices...), the cooling energy needs and the available renewable energy systems such as PV systems, solar DHW systems, cogeneration or the use of biomass. In this preliminary study, the heating needs are focused.

\subsection{Exergy analysis}

Commonly, the use of energy refers to the first law of thermodynamics which states that energy is stored in every device and process and can neither be consumed nor destroyed; it can only be transformed [10]. However, this concept is "inadequate for depicting some important aspects of energy resource utilization" [10] as building performance. The exergy indicates the maximum work potential of a system under determined conditions. There are no conventions widely accepted to define the exergy concept but in the present contribution the exergy analysis proposed by [11] is used. Exergy (Ex) expressed in $\mathrm{J} / \mathrm{kg}$ is defined as: 


$$
E x=\left(H-H_{0}\right)-\left(T_{0}+273.15\right) *\left(S-S_{0}\right)
$$

where $\mathrm{H}$ stands for the enthalpy $[\mathrm{J} / \mathrm{kg}], \mathrm{S}$ for the entropy $[\mathrm{J} / \mathrm{kg} / \mathrm{K}]$, T for the temperature $\left[{ }^{\circ} \mathrm{C}\right]$ and the subscript ${ }_{0}$ the reference or 'dead' state. In this study, this reference state is defined as the average annual temperature of a location with a pressure of 1 atmosphere. For the fuel exergy calculations, the air used has a relative humidity of $70 \%$ [12] and a composition defined according to [13].

\subsection{Buildings description}

Three kinds of buildings are investigated: terraced house, semi-detached house and free-standing houses. These three kinds of houses represent about $82 \%$ of the Belgian building stock [14]. The main characteristics of the buildings are available in Table 1 . There are two terraced houses (Buildings \#1 and \#4): one insulated (Building \#4) the other (Building \#1) no, to mark the influence of insulation on the heating needs. Moreover the total heating system efficiency $\left(\epsilon_{H S}\right)$ has quite a large influence on the building specific heating use. This heating system efficiency is the product of the heating system, distribution and emission efficiencies. Once again the variation is clear between Building \#1 and \#4.

\begin{tabular}{|c|c|c|c|c|}
\hline Building & $\begin{array}{l}\text { Heated } \\
\text { area }(\mathrm{HA})\end{array}$ & $\begin{array}{l}\text { Heated } \\
\text { volume }\end{array}$ & $\begin{array}{l}\text { Heating } \\
\text { needs }\end{array}$ & $\begin{array}{l}\text { Heating system and effi- } \\
\text { ciency }\end{array}$ \\
\hline \#1 Terraced & $209 m^{2}$ & $745 \mathrm{~m}^{3}$ & $\begin{array}{l}70023 \\
{[\mathrm{kWh} / \text { year }]}\end{array}$ & $\begin{array}{l}\text { Old NG boiler, no distri- } \\
\text { bution insulation, } \epsilon_{H S}= \\
0.58\end{array}$ \\
\hline $\begin{array}{lr}\# 2 & \text { Semi- } \\
\text { detached } & \text { and } \\
\text { insulated } & \end{array}$ & $294 m^{2}$ & $892 \mathrm{~m}^{3}$ & $\begin{array}{l}37926 \\
{[\mathrm{kWh} / \text { year }]}\end{array}$ & $\begin{array}{l}\text { NG condensing boiler, } \\
\epsilon_{H S}=0.8\end{array}$ \\
\hline \#3 Free-standing & $153 \mathrm{~m}^{2}$ & $435 \mathrm{~m}^{3}$ & $\begin{array}{l}69986 \\
{[\mathrm{kWh} / \text { year }]}\end{array}$ & $\begin{array}{l}\text { Old Oil boiler, } \epsilon_{H S}= \\
0.72\end{array}$ \\
\hline \#4 Terraced & $101 \mathrm{~m}^{2}$ & $270 \mathrm{~m}^{3}$ & $\begin{array}{l}32685 \\
{[\mathrm{kWh} / \text { year }]}\end{array}$ & $\begin{array}{l}\text { NG condensing boiler, } \\
\text { floor heating, } \epsilon_{H S}=0.85\end{array}$ \\
\hline
\end{tabular}

Table 1: Buildings characteristics

In all these buildings, a consumption profile is set up for a couple with one child. This parameter involves fixed heat gains due to occupation. All 


\begin{tabular}{llllllllllllll}
\hline \multicolumn{2}{l}{ Month of the year } & 1 & 2 & 3 & 4 & 5 & 6 & 7 & 8 & 9 & 10 & 11 & 12 \\
\hline $\begin{array}{l}\text { Temperature } \\
\text { Brussels }\left[{ }^{\circ} \mathrm{C}\right]\end{array}$ & for & 2.7 & 3.1 & 5.5 & 8.2 & 12.8 & 14.9 & 16.8 & 16.4 & 14 & 10 & 5.2 & 3.4 \\
$\begin{array}{l}\text { Temperature } \\
\text { Bastogne [ }{ }^{\circ} \mathrm{C} \text { ] }\end{array}$ & for & 0 & 0.2 & 3.2 & 5.8 & 11.1 & 13.6 & 15.4 & 14.2 & 11.3 & 7.4 & 2.7 & 0.7 \\
\hline
\end{tabular}

Table 2: Average monthly temperatures for different locations

the wall characteristics use for the assessment of transmission heat losses are available in Annex A. No mechanical ventilation is considered to not favour one building considering low heat losses ventilation.

\subsection{Weather data}

Belgian weather data are available [15] month by month for two locations (Table 2). In Belgium, it is considered the amount of heating hours per year is about 5800, typically from January until May and from October to December, so the mean temperature is respectively 6.4 and $3.9^{\circ} \mathrm{C}$ for the cities of Brussels and Bastogne. In this contribution, only the average annual temperature during the heating period is considered as reference state for the results of the exergy analysis but a monthly or weekly average may be used.

\subsection{Heating systems}

In this contribution, several heating systems are considered to improve the buildings and rank them in an energy and an exergy point of view. In this study water temperature produced is considered at high temperature, $60{ }^{\circ} \mathrm{C}$, for conventional radiators or DHW (to consider the emission and distribution losses) or at low temperature, $35^{\circ} \mathrm{C}$, for heating floor.

\subsubsection{Electric heating}

The simplest and cheapest heating system is the electric heating system which consists in heating resistors. Its energy and exergy building efficiency is assumed to one while all heat losses in the installation are assumed used to heat the walls/rooms of the building.

\subsubsection{Heat pumps}

Heat pumps consume power to produce heat. Therefore, its energy and exergy efficiencies depend on its coefficient of performance (COP) which is 
defined as the ratio of the heat generated $(\dot{Q})$ over electrical energy consumed i.e. in a first approximation the energy consumed by the compressor $(\dot{W})$ neglecting the command system and the possible resistor to maintain at temperature the compressor when it is not used. This parameter generally depends on the kind of heat pump (air/air, air/water, etc), the ambient temperature and the fluid temperature generated. In this study, an air/water heat pump is considered because this kind of heat pump is widely used in buildings during a renovation step while it does not require extra water/ground source. Complementary heat storage is available to reduce the size of the heat pump (and so the investment cost) and the number of start and stop cycles which reduces the compressor lifespan and the mean COP. Nominal air / water heat pump COP depends mainly on the outside temperature (depending on the climate) and the temperature of water generated and so the kind of heating emissions systems: heating floor with low temperature requirements or radiators with high temperature requirements. Previous work [16] intends to assess the COP in several partial load and weather conditions for a large amount of heat pumps available on the Belgian market. Therefore COP can be extrapolated in function of the climate conditions or heating emissions systems. In this case, heating systems with a heating floor is considered has its annual average COP of 3.3 whereas heat pump coupled to conventional radiators has an annual average COP of 2.7. Notice in the buildings studied, the DHW represent less $10 \%$ of the total energy needs. The average annual COP of heat pump used herein considers the reduced COP for the DHW production due to higher water temperature production.

\subsubsection{Boilers}

Buildings boilers use fuel (natural gas, gasoil, wood pellets, etc) to produce generally hot air or water. The exergy supplied to them depends on the fuel exergy. In the case of liquid and solid fuel, some empiric correlations are available (Equations 2 and 3) to estimate their exergy in function of the mass composition such as carbon $(\mathrm{C} \%)$, oxygen $(\mathrm{O} \%)$, hydrogen $(\mathrm{H} \%)$, nitrogen $(\mathrm{N} \%)$ or sulfur $(\mathrm{S} \%)$ [17]. In the case of natural gas, the chemical exergy depends on its gases components. As for the heat pumps, the water level temperature used to heat buildings has an influence on the energetic and exergy efficiency of the system especially if a condensation boiler is used that is conventionally the case in a renovation step in buildings. In this study, a boiler efficiency of $90 \%$ is assumed for all fuels considered; considering all 
boilers are condensing boilers. Solid fuel exergy content is assessed by:

$$
E_{\text {Solid }}=\frac{1.0438+0.1882 \frac{H \%}{C \%}-0.2509\left(1+0.7256 \frac{H \%}{C \%}+0.0383 \frac{N \%}{C \%}\right.}{1-0.3035 \frac{O \%}{C \%}} \cdot\left(L V H_{0}+W \% \cdot \Delta_{h}\right)
$$

where W stand for humidity fraction in the solid fuel, $\Delta_{h}$ for the enthalpy of evaporation of the water at the reference temperature and $L H V_{0}$ for low heating value. Liquid fuel exergy content is assessed by:

$E_{\text {Liquid }}=\left\{1.0401+0.1728 \frac{H \%}{C \%}-0.0432 \frac{O \%}{C \%}+0.2169 \frac{S \%}{C \%} \cdot\left(1-2.0628 \frac{H \%}{C \%}\right)\right\} \cdot L V H_{0}$

To be complete, it is reminded to the reader that the LHV is conventionally defined at a temperature reference of $25{ }^{\circ} \mathrm{C}$. Therefore to consider another temperature reference for the exergy calculations, it is assumed that the following correction is applied:

$$
L H V_{0}=L H V_{25^{\circ} \mathrm{C}}+C_{p} \Delta_{T}
$$

where $C_{p}$ is the fuel specific heat capacity $[\mathrm{J} /(\mathrm{kg} \mathrm{K})]$, assumed as constant for low temperature variation; and $\Delta_{T}$ the temperature difference between $25{ }^{\circ} \mathrm{C}$ and the exergy reference. The specific heat capacity is respectively $1.23 \mathrm{~kJ} /(\mathrm{kg} \mathrm{K})$ and $1.85 \mathrm{~kJ} /(\mathrm{kg} \mathrm{K})$ for wood pellets [18] and heating oil [19].

\subsubsection{District Heating Network}

Hot water produced by a delocalized plant is supplied by pipes to buildings through by a substation. A substation is composed of a heat exchanger, valves and some electronic or mechanical regulation. It is assumed a mean energy efficiency $\left(\epsilon_{S S}\right)$ of the residential substation of $98 \%$ [20] and a heat exchanger pinch point of $3{ }^{\circ} \mathrm{C}[20]$. The amount of exergy supplied to the building mainly depends on the water temperature used in the buildings. Indeed the pressure losses in a substation are generally about 300 mbar and have a negligible influence on the exergy.

\subsubsection{Emissions and distribution systems}

Efficiency of emission system is assumed to be a value of 0.95 for radiators and 0.99 for heating floor $[21,22]$. On the other hand, the efficiency of the distribution system is assumed 0.92 for radiators and 0.95 for heating floor $[21,22]$. 


\subsection{Domestic heating water systems and insulation}

In the buildings studied, there is a DHW tank. This allows the use of lower heating system peak power and therefore lower investments, especially for the heat pumps. But theses tanks introduce heat losses which are considered.

On another hand, a convenient way to reduce the energy consumption is to insulate the building by insulating the roof and/or the walls or replacing single glazing windows by double gazing window. However, building insulation requires a lot of investment and sometimes has a negative influence on the space available in the building or on the visual aspect of them. Despite it, insulation should be the first step to perform to renovate a building to decrease its heating needs.

\subsection{Supplied energy and exergy flux}

\subsubsection{Electricity}

Electricity is considered as pure exergy while all the available electricity can be converted into work. However, it has to be produced by plants such as gas turbines, nuclear plants, steam plants... In Belgium, the mean efficiency to produce electricity and transport it to a building is $40 \%$ [23]. Therefore electricity supplied to a building has to be inflated by a factor of 2.5 to consider these losses. For an exergy point of view, it is proposed to inflate this last factor by the ratio of the exergy by the LHV of natural gas.

\subsubsection{Fuel energy and exergy}

To assess the exergy flux supplied to the building by the previous correlations available in this paper, the fuel characteristics must be known. The energy flux supplied is determined by its LHV. A typical Belgian composition of natural gas (and its LHV) is available in Table 3 [24].

\begin{tabular}{lllllllllllll}
\hline $\mathrm{N} 2$ & $\mathrm{CO} 2$ & $\mathrm{CH} 4$ & $\mathrm{C} 2 \mathrm{H} 6$ & $\mathrm{C} 3 \mathrm{H} 8$ & $\mathrm{iC} 4$ & $\mathrm{nC} 4$ & $\mathrm{iC} 5$ & $\mathrm{nC} 5$ & $\mathrm{C} 6+$ & $\mathrm{O} 2$ & $\mathrm{He}$ & $L H V_{0}[\mathrm{~kJ}]$ \\
\hline 1.329 & 1.391 & 91.247 & 4.488 & 0.935 & 0.28 & 0.14 & 0.055 & 0.03 & 0.09 & 0 & 0.017 & 46725 \\
\hline
\end{tabular}

Table 3: Gas volume fraction and LHV of common natural gas used in Belgian boilers.

Herein, a simplified wood pellet mass composition is considered: $50 \%$ of C, $6 \%$ of $\mathrm{H}$ and $44 \%$ of $\mathrm{O}$. Nitrogen or sulfur content are neglected while they represent generally less than $2 \%$ in the main wood pellet certifications such as EN 14961-2, Din+ or NF norms. Analysis of wood pellets used in

the DHN of the University of Liège according to EN15104, EN15289 norms 
$[25,26]$ are available in Table 4 and confirm this assumption. The $L H V_{0}$ considered is $17.5 \mathrm{MJ} / \mathrm{kg}[27]$.

\begin{tabular}{lllllll}
\hline & $\mathrm{C} \%$ & $\mathrm{H} \%$ & $\mathrm{~N} \%$ & $\mathrm{O} \%$ & $\mathrm{~S} \%$ & $\mathrm{~W} \%$ \\
\hline Wood sample \# 1 [25] & 50.2 & 6.1 & 0.09 & 43.2 & 0.009 & 7.6 \\
Wood sample \# 2 [26] & 50.5 & 6 & 0.03 & 43.1 & 0.021 & 6.5 \\
\hline
\end{tabular}

Table 4: Mass composition of DIN+ wood pellets

Since the first of January 2016, a Directive (2009/30/CE) of the European Commission involves the use of heating oil with a maximum sulfur content of $50 \mathrm{ppm}$, therefore its composition could be assumed of $86,5 \%$ of $\mathrm{C}$ and $13,5 \%$ of $\mathrm{H}$ [28]. $L H V_{0}$ of heating oil is considered equal to $42.6 \mathrm{MJ} / \mathrm{kg}$ [29].

\subsubsection{District heating network}

As for as the electricity, the primary energy/exergy required to supply the building depends on the way of production and the transport. The heat losses due to transport $\left(H L_{D H N}\right)$ from plant to buildings vary depending on the linear heat density of the DHN which is defined as the ratio of the annual heat delivered to the total length of the DHN pipes: from $5 \%$ for high linear density up to $25 \%$ for low linear density [30-32]. In this study, transport efficiency is considered to $10 \%$. Moreover the DHN can be supplied by several systems such as a dedicated boiler (fuelled by renewable or no fuels) or by heat recovery performed on a power plant. In the case of a DHN supplied by the boiler, the energy efficiency is lower than $80 \%$ due to production, transport and substation efficiencies. Currently, this configuration system makes sense only if a renewable fuel is used to take advantage of the related policies of the fuel use for economic, environmental and social point of view. These aspects are not focused on this study but the reader interested can refer to [33] for more information. If a heat recovery is performed on a power plant, the energy efficiency of the plant could reach $92 \%$ [5]. But a high efficiency power plant supplied by natural gas has currently an efficiency of $55 \%$ for power only plant. For CHP activity, the electricity efficiency drops from 55 to $47.5 \%$ [34] considering a DHN at medium temperature to supply buildings with medium and low-grade energy $\left(30-80^{\circ} \mathrm{C}\right)$. Finally, a recovery thermal efficiency is considered equal to $80 \%$ [35]. It can be as a heat pump, so a unit of electricity (here lost due to cogeneration activity) recovers about 5.5 units of heat from the plant. The final energy supplied to the building is 
assessed by:

$$
C O P_{D H N_{0}}=5.5 \cdot\left(1-H L_{D H N}\right) \cdot \epsilon_{S S}
$$

It is proposed to assume this factor to 4.8, which corresponds to heat losses for the transport of about $10 \%$. This figure corresponds to a typical city or medium town fed by DHN. Notice, this factor could be higher in the case where the heat is recovered from waste. As electricity or heat pumps, this last figure to be inflated by a factor of 2.5.

\subsection{Energy and exergy needs}

The energy requirements to maintain user comfort in the building are assessed by the EPB Belgian software. The building exergy needs (Ex $x_{\text {building }}$ ) is defined [21] as the exergy load of the building (losses to the environment) and it is assessed by:

$$
E x_{\text {building }}=\left(1-\frac{273.15+T_{0}}{273.15+T_{\text {building }}}\right) * E R
$$

where ER stands for the energy requirements calculated by the EPB software and $T_{\text {building }}$ is the mean temperature inside the building assumed herein to $20{ }^{\circ} \mathrm{C}$.

\section{Results and discussion}

\subsection{Energy and exergy analysis}

EBP software assesses the energy consumption of each building and the results of the specific energy use (defined in section 2.1) are available in Figure 1. To get the specific energy use, the heating needs of the building (Table 1) are divided by the total heating system efficiency (defined in 2.3) and the heated area. The insulation and the performing heating systems installation of the building \#4 reduce significantly the specific energy use compared to building \#1 (same building kind). Therefore the first action to reduce the specific energy (exergy) use is to insulate the building. This can be seen also for the Building \#2 which has a higher area of losses but which have the lower specific energy use while its mean envelope heat transfer coefficient is lower due to insulation. However, the insulation could sometimes be very costly or difficult to implement in old building especially if the insulation has to be performed inside the buildingsfor urbanistic reasons. Indeed this 


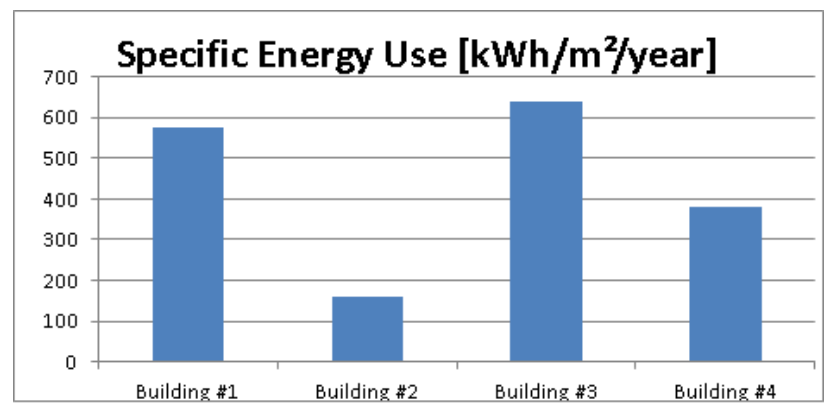

Figure 1: Specific energy use of four buildings studied.

insulation reduces the available living space and some thermal bridge can remain.

Another approach is to investigate for the same energy needs of buildings (same insulation) the different heating systems studied in the previous section (Figure 2). Moreover two emission heating systems are considered to see the influence of the emission and distribution system efficiencies of the building: heating floor (denoted LT) and medium temperature radiators (denoted HT). As expected, the electric heating is the worst heating systems for the primary energy use. All the boiler systems have roughly the same primary energy use for the same emission heating system. Heat pump and DHN as heating system reduce widely the primary energy use especially if the emission heating system is the floor heating. The best case is the use of DHN with floor heating.

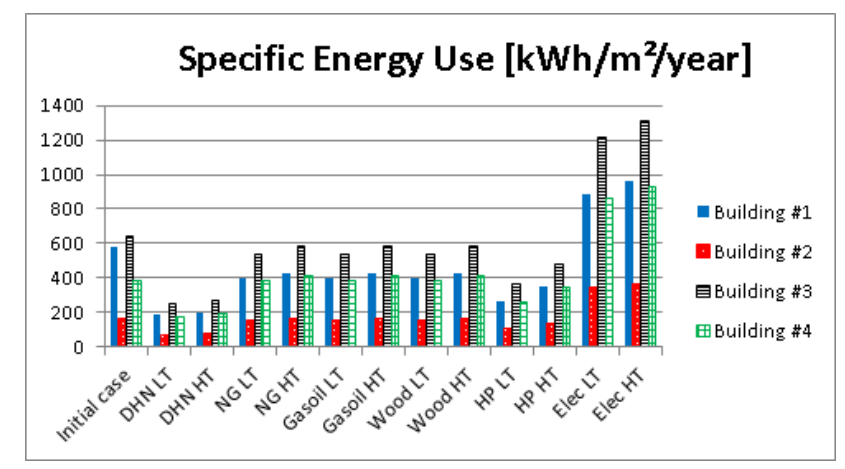

Figure 2: Specific energy use for different heating systems considered for the four buildings studied.

For each heating system the exergy building efficiency is higher when 
a heating floor is used while the emissions and distribution efficiency are higher in this case (Figure 3). As for the specific energy use, the best case is when the heating needs are supplied by a DHN to a floor heating. In this approach, the insulation has no influence on the exergy building efficiency while this efficiency assesses the way of the exergy is destroyed. Higher exergy building needs lead to higher exergy production needs. The exergy building efficiency is assumed for the two climate conditions studied (Figure 3). Lower is the temperature reference state, higher is the exergy building efficiency due to a higher $\tau$. It's why it could sometimes be difficult to use exergy in buildings while the exergy building efficiency of a house (same heating systems, insulation, etc) varies with the climate conditions. Of course, a common reference could be defined to overcome this.

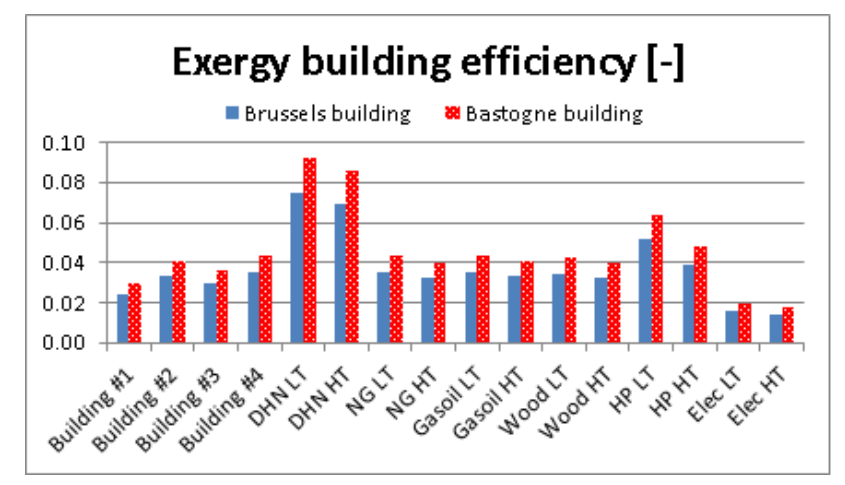

Figure 3: Exergy building efficiency for two different climates and in function of the heating system.

To rank the studied heating systems, it is proposed to compare the different ones with a reference case: condensing boiler with heating floor denoted NG LT (Figure 4). Therefore, lower is the heating system performance ratio, higher is its efficiency. Once again, heat pumps and DHN are the best heating system. DHN can reduce the energy/exergy needs compared to the reference case by a factor 2 .

Considering the EPB level currently used (Table 5), buildings can improve its level (by one or more levels) simply by replacing its current old boiler by a substation linked to a DHN.

Thanks to the previous assessment of specific energy use, specific exergy needs can be assessed considering the exergy fuel calculated by the section 2.7. For sake of simplicity only the values for Buildings \#2 are available in 


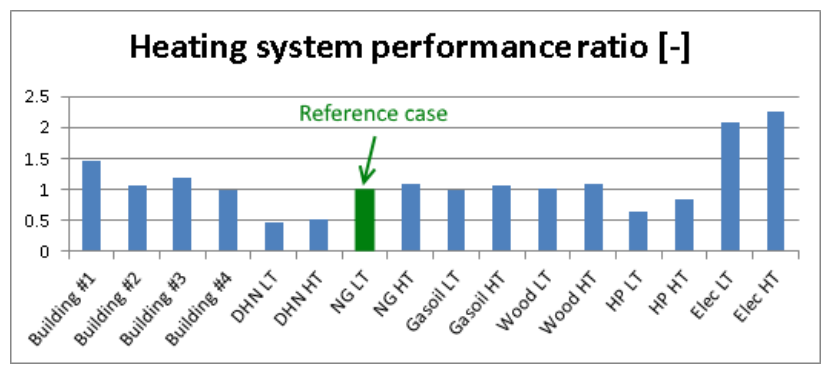

Figure 4: Heating system performance ratio compared to natural gas boiler with heating floor (lower value is better

Table 5: EPB specific energy use levels in Belgium

\begin{tabular}{|c|c|c|c|c|c|c|c|}
\hline Level & $\mathrm{A}++$ & $\mathrm{A}+$ & B & $\mathrm{C}$ & $\mathrm{D}$ & $\mathrm{E}$ & $\mathrm{F}$ \\
\hline $\begin{array}{l}\text { Specific } \\
\text { energy use } \\
{\left[k W h / m^{2}\right]}\end{array}$ & $\leq 0$ & ]45..85] & ]85..170] & ]170..255] & ]255..340] & ]340..425] & ]425..510] \\
\hline
\end{tabular}

Figure 5 but the discussion remains the same for the other ones. The specific exergy use values are higher than specific energy needs due to higher exergy content of the fuel. The conclusions are the same as previously discussed for the best heating systems.

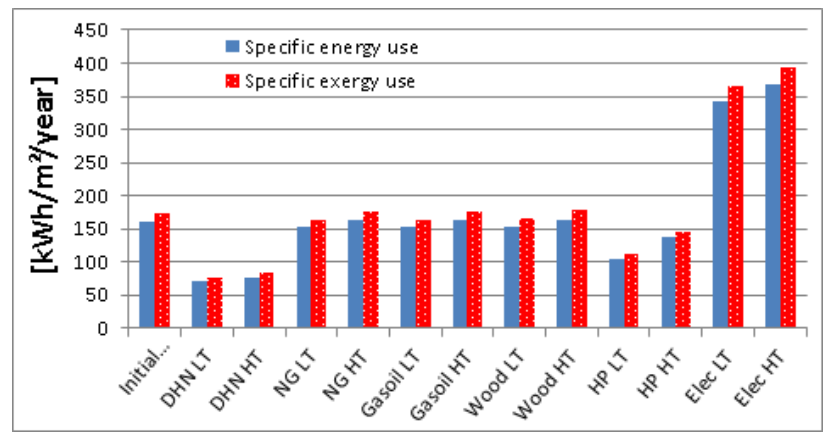

Figure 5: Specific energy and exergy needs for several heating systems in the Building \#2.

\subsection{Environmental analysis}

To complete the discussion, environmental analysis is also performed. The Belgian $\mathrm{CO}_{2}$ emissions based on primary energy due to several fuels' use (production, transport and combustion) are reported in Table 6. In the 
case of DHN, the emissions of electricity are considered. They are inflated by the lower efficiency power production due to heat recovery and lowered by the factor defined in Section 2.7.1.

\begin{tabular}{lrrrrr}
\hline & Electricity & Natural gas & Gasoil & Wood & DHN \\
\hline Energy based $[\mathrm{g} / \mathrm{kWh}]$ & $456[23]$ & $251[36]$ & $306[36]$ & $42[37]$ & 112.3 \\
\hline
\end{tabular}

Table 6: $\mathrm{CO}_{2}$ emissions energy based.

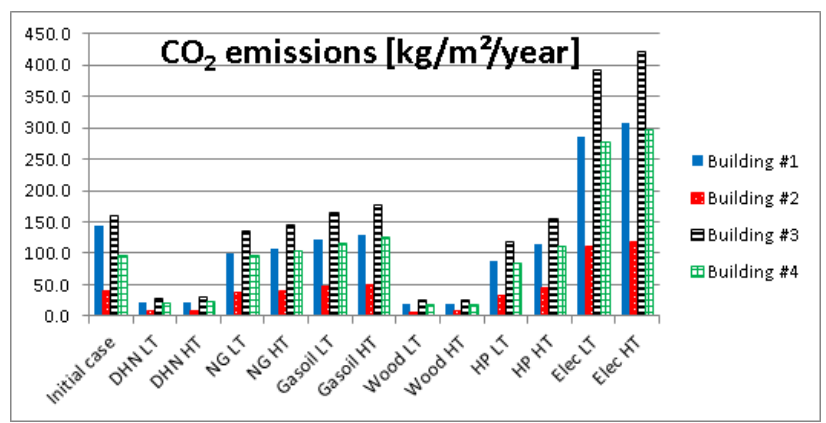

Figure 6: Annual $\mathrm{CO}_{2}$ emissions for the different heating systems configuration for the four buildings studied.

Based on these figures, the specific $\mathrm{CO}_{2}$ emissions (kg per square meter of the building) are assessed for the four buildings considered (Figure 6). As for the energy, an insulated building reduces mainly specific $\mathrm{CO}_{2}$ emissions (comparison between Building \#1 and \#4 or Building \#2). Due to lower emission the use of wood boiler involves a wide reduction of $\mathrm{CO}_{2}$ emissions compared to the other heating systems.

\section{Conclusions and perspectives}

Energy in buildings represents about $40 \%$ of the total European energy use and $\mathrm{CO}_{2}$ emissions. To improve buildings, energy performance of buildings software has been developed in Belgium to assess the best ways of improvement. However, this approach is based on the first law of thermodynamics and considers only the quantity of energy used without considering its "quality" and leads to a lack of information about the energy conversion processes such as production, distribution or emission inside a building. The exergy analysis of a system, based on first and second thermodynamic laws, 
can be used to overcome this. Under some assumptions, specific energy and exergy use of buildings are assessed. First the insulation has a favorable effect only on the primary energy use and on the $\mathrm{CO}_{2}$ emissions. Indeed the exergy building efficiency depends only on the way of destruction of the exergy and does not depend on the energy building needs. It has been shown the best heating systems is a DHN connection followed by heat pumps according to the energy and exergy point of view. In the first case, it is due to the fact a part of available heat is recovered in power plant increasing the use efficiency of the fuel and in the second case, low-grade temperature is used. Finally, the use of wood and DHN allows a wide reduction of $\mathrm{CO}_{2}$ emissions while it is a renewable energy with a low $\mathrm{CO}_{2}$ emission factor for wood and an improve fuel use for DHN fed by a cogeneration power plant. As perspective, a detailed study monthly or weekly base should be considered to catch more precisely the influence of the climate conditions on the exergy building efficiency. To conclude the best energy is the one which is not used. This leads

to insulate or to improve the heating systems in the building. In the case of exergy, the best way is not to destroy it in the whole life cycle of heating i.e. from production to emission.

\section{References}

[1] ADEME, Perspectives énergétiques mondiales . Les politiques d'efficacité énergétique dans le Monde : ce qui fonctionne et ce qui ne fonctionne pas, Tech. rep. (2013).

[2] European Union - Energy efficiency in buildings (2010). URL http://ec.europa.eu/energy/efficiency/buildings/ buildings $\left\{\backslash \_\right\}$en.htm

[3] C. A. Brebbia, A. M. Marinov, A. A. Mammoli, C. A. Safta, Energy and Sustainability IV, WIT transactions on ecology and the environment, Computational Mechanics, 2013.

URL https://books.google.be/books?id=MRWkN3X00x8C

[4] K. Sartor, Y. Restivo, P. Ngendakumana, P. Dewallef, Prediction of SOx and NOx emissions from a medium size biomass boiler, Biomass and Bioenergy 65 (2014) 91-100. doi:10.1016/j.biombioe.2014.04.013.

[5] I. Dincer, M. Rosen, Exergy Analysis of Renewable Energy Systems, 2013. doi:10.1016/b978-0-08-097089-9.00011-5. 
[6] E. Union, EU Buildings Database, Tech. rep. (2015). URL http://ec.europa.eu/energy/en/eu-buildings-database

[7] Eurostat, Detailed statistics on the EU and candidate countries, and various statistical publications for sale. (2017).

URL http://ec.europa.eu/eurostat

[8] E. E. Agency, Efficiency of conventional thermal electricity and heat production, Tech. rep., European Environment Agency (2015). URL http://www. eea.europa.eu/data-and-maps/indicators/ efficiency-of-conventional-thermal-electricity-generation-3/ assessment

[9] W. Region, La réglementation wallonne - PEB. URL http://energie.wallonie.be/fr/ la-reglementation-wallonne-sur-la-peb.html?IDC=7224

[10] M. J. Moran, H. N. Shapiro, Fundamentals of engineering thermodynamics (2009).

[11] T. J. Kotas, EXERGY CONCEPTS FOR THERMAL PLANTS. (1980). doi:10.1016/0142-727X(80)90028-4.

[12] J. Szargut, D. R. Morris, F. R. Steward, Exergy analysis of thermal, chemical, and metallurgical processes, Hemisphere, 1988.

[13] I. S. Ertesvåg, Sensitivity of chemical exergy for atmospheric gases and gaseous fuels to variations in ambient conditions, Energy Convers. Manag. 48 (7) (2007) 1983-1995. doi:10.1016/j.enconman.2007.01.005. URL http://www.sciencedirect.com/science/article/pii/ S0196890407000295

[14] I. Asbl, BILAN ÉNERGÉTIQUE DE LA WALLONIE 2009 - BILAN DE CONSOMMATION DU SECTEUR RESIDENTIEL, Tech. rep. (2011).

[15] MeteoBelgique, Climatogrammes (2016).

URL http://www.meteobelgique.com/article/ donnees-statistiques/climatogramme.html?staticfile= climatology-climatogram $\left\{\backslash_{-}\right\}$fr.php 
[16] S. GENDEBIEN, F. RANSY, E. GEORGES, V. LEMORT, Flexipac Project: Database of parameters for modelling residential heat pumps., Tech. rep. (2014).

[17] T. Kotas, The Exergy Method of Thermal Plant Analysis, Elsevier, 1985. doi:10.1016/B978-0-408-01350-5.50016-7.

URL http://www.sciencedirect.com/science/article/pii/ B9780408013505500167

[18] W. Guo, C. J. Lim, X. Bi, S. Sokhansanj, S. Melin, Determination of effective thermal conductivity and specific heat capacity of wood pellets, Fuel 103 (2013) 347-355. doi:10.1016/j.fuel.2012.08.037.

URL http://www.sciencedirect.com/science/article/pii/ S0016236112006746

[19] S. Sundarapandian, G. Devaradjane, Performance and Emission Analysis of Bio Diesel Operated CI Engine, Eng. Comput. Archit. 1 (2) (2007) $1-22$.

[20] D. energy Agency, Technology data for energy plants - Individual Heating Plants and Energy Transport, Tech. rep. (2012).

[21] Schmidt, Design of Low Exergy Buildings - Method and Pre-Design Tool, Int. J. Low Energy Sustain. Build. (3) (2004) 1-47.

[22] H. Torio, D. Schmidt, Detailed Exergy Assessment Guidebook for the Built Environment, Tech. rep., Fraunhofer (2011).

[23] W. Region, http://www.energieplus-lesite.be/index.php?id=15568 (2007).

[24] Fluxys, Fluxys operational data (2016).

URL http://www.fluxys.com/belgium/en/Services/ ServicesForConnectedCompanies/OperationalData/ OperationalData

[25] AIB-Vinçotte, Chaudière biomasse du Sart Tilman - Test de performance - Rapport d'essai, Tech. rep. (2012).

[26] AIB-Vinçotte, Chaudière biomasse du Sart Tilman - Test de performance - Rapport d'essai, Tech. rep. (2014). 
[27] L. Sjaak van, L. loo handbook Jaap Koppejan, The Handbook of Biomass Combustion and Co-firing (2010).

[28] C. Küchen, K. Spitzmüller, Heating Oil, in: Ullmann's Encycl. Ind. Chem., Wiley-VCH Verlag GmbH \& Co. KGaA, 2000.

[29] Handbook of Energy, Elsevier, 2013. doi:10.1016/B978-0-08-0464053.00006-1.

URL http://www.sciencedirect.com/science/article/pii/ B9780080464053000061

[30] K. Sartor, S. Quoilin, P. Dewallef, Simulation and optimization of a CHP biomass plant and district heating network, Appl. Energy 130 (2014) 474-483. doi:10.1016/j.apenergy.2014.01.097.

[31] S. Frederiksen, S. Werner, Fjärrvärme : Teori, teknik och funktion, Ph.D. thesis, Lund University, Sweden (1993).

[32] J. E. Thorsen, C. H. Christiansen, M. Brand, P. K. Olesen, C. T. Larsen, Experiences On Low-Temperature District Heating In Lystrup Denmark, Portorož, Slovenia, 2011.

[33] B. Rezaie, M. A. Rosen, District heating and cooling: Review of technology and potential enhancements, Appl. Energy 93 (2012) 2-10. doi:10.1016/j.apenergy.2011.04.020.

[34] EURELECTRIC "Preservation of Resources" Working Group's Collaboration, VGB, Efficiency in electricity generation, Tech. rep., EURELECTRIC (2003).

URL http://www.eurelectric.org/Download/Download.aspx? Document ID $=13549$

[35] R. R. Academy, CHP - Cogeneration Power, Tech. rep. (2015).

URL www.renac.de/fileadmin/renac/CHP $\left\{\backslash_{-}\right\}$ENG $\left\{\backslash_{-}\right\}$final.pdf

[36] CWAPE, CWaPE.

URL www. cwape.be

[37] ADEME, Base carbone v11, Tech. rep., ADEME (2014).

URL http://www.bilans-ges.ademe.fr/static/documents/\{\\% \}5BBaseCarbone $\left\{\backslash \%\right.$ FDDocumentationg $\left\{\backslash^{\prime}\{\mathrm{e}\}\right\} \mathrm{n}\left\{\backslash^{\prime}\{\mathrm{e}\}\right\}$ ralev11.0. pdf 
6. Appendix : Building characteristics 


\author{
Building \#1 \\ $2 \mathrm{x}$ glazed windows (wood) \\ $2 \mathrm{x}$ blazed window \\ Door \\ Front wall \\ Rear wall \\ Kitchen wall \\ Second rear wall \\ Cave wall \\ Cave wall \\ Floor on cave \\ Floor on ground \\ Window \\ Rear door \\ Window \\ Cave door \\ Tiled roof \\ Flat roof \\ Roof \\ Window
}

Total

Mean U value $\left(\mathrm{W} / \mathrm{m}^{2} / \mathrm{K}\right)$

Building \#2

Insulated roof $(16 \mathrm{~cm})$

Insulated wall $(6 \mathrm{~cm})$

Stone wall

Wall

Wall

Cave brick wall

Cave wall

Wall

Cave floor

Cave floor

Insulated floor

Cave floor

$2 \mathrm{x}$ glazed windows

2x glazed windows (alu)

Door

Total

Mean $U$ value $\left(\mathrm{W} / \mathrm{m}^{2} / \mathrm{K}\right)$
A $\left(\mathbf{m}^{\mathbf{2}}\right) \quad \mathrm{U}$

$24.7 \quad 1.85$

$24.4 \quad 2.00$

$2.2 \quad 2.91$

$\begin{array}{ll}39.7 & 1.77\end{array}$

$25.7 \quad 1.77$

8.21 .60

$82.9 \quad 1.77$

$2.3 \quad 1.60$

$\begin{array}{ll}1.7 & 1.70\end{array}$

$32.2 \quad 2.10$

$\begin{array}{ll}62.9 & 2.00\end{array}$

$0.6 \quad 5.70$

$2.9 \quad 5.03$

$0.4 \quad 5.03$

$\begin{array}{ll}1.6 & 5.03\end{array}$

$34.4 \quad 3.16$

$31.6 \quad 3.54$

$\begin{array}{ll}37 & 1.70\end{array}$

$3.1 \quad 5.03$

418.5

2.16

\section{A $\left(\mathbf{m}^{\mathbf{2}}\right) \quad \mathbf{U}$}

152.9

133.44

27.45

34.09

17.98

4.26

5.51

4.17

65.28

84.47

$\begin{array}{ll}7.26 & 0.18\end{array}$

$5.21 \quad 2.22$

$45.98 \quad 2.57$

$3.38 \quad 3.83$

$1.65 \quad 2.94$

$59 \mathbf{3}_{0} 03$

1.25

\section{Building \#3}

Roof

Rear roof

Slate wall

Stone wall

Wall

Wall

Cave wall

Insulated wall

Insulated floor

Floor on cave

$2 \mathrm{x}$ glazed windows (wood)

Door

Read door

Annex door

Cave door

Total

Mean U value $\left(\mathrm{W} / \mathrm{m}^{2} / \mathrm{K}\right)$
A $\left(\mathbf{m}^{\mathbf{2}}\right) \quad \mathrm{U}$

$72.08 \quad 2$

$9.45 \quad 0.92$

$76.87 \quad 1.41$

$43.62 \quad 1.81$

$105.65 \quad 2.48$

$20.64 \quad 2.48$

$5.08 \quad 2.97$

$\begin{array}{ll}13.89 & 0.33\end{array}$

$62.41 \quad 0.78$

$18.89 \quad 2.1$

$12.82 \quad 3.1$

$1.89 \quad 3.64$

$4.71 \quad 3.98$

$2.11 \quad 2.94$

$1.26 \quad 2.94$

451.37

1.85

\section{Building \#4}

Roof part 1

Roof part 2

Front wall

Rear wall

Annex wall

Garage wall

Ceil wall

Ceil wall

Floor

Floor

Door

Kitchen door

Front window

Kitchen windows

Window

One blazed window

Door

Total

Mean U value $\left(\mathrm{W} / \mathrm{m}^{2} / \mathrm{K}\right)$
A $\left(\mathbf{m}^{2}\right) \quad \mathrm{U}$

$21.2 \quad 4.11$

$22.7 \quad 4.11$

$30.74 \quad 1.01$

$14.3 \quad 1.01$

$24.07 \quad 1.45$

$20.99 \quad 1.01$

$11.19 \quad 1.1$

$11.19 \quad 1.1$

$\begin{array}{ll}35.2 & 0.57\end{array}$

$\begin{array}{ll}15.8 & 0.68\end{array}$

$\begin{array}{ll}1.91 & 1.73\end{array}$

$\begin{array}{ll}1.8 & 1.55\end{array}$

$10.78 \quad 2.31$

$0.9 \quad 1.55$

$\begin{array}{ll}1.6 & 2.45\end{array}$

$0.38 \quad 4.65$

$1.35 \quad 2.79$

226.1

1.68 